\title{
All-Polycarbonate Thermoplastic Elastomers Based on Triblock Copolymers Derived from Triethylborane-Mediated Sequential Copolymerization of $\mathrm{CO}_{2}$ with Various Epoxides
}

\author{
Mingchen Jia, Dongyue Zhang, Gijs W. de Kort, Carolus H. R. M. Wilsens, Sanjay Rastogi, \\ Nikos Hadjichristidis, Yves Gnanou,* and Xiaoshuang Feng*
}

Cite This: https://dx.doi.org/10.1021/acs.macromol.0c01068

Read Online

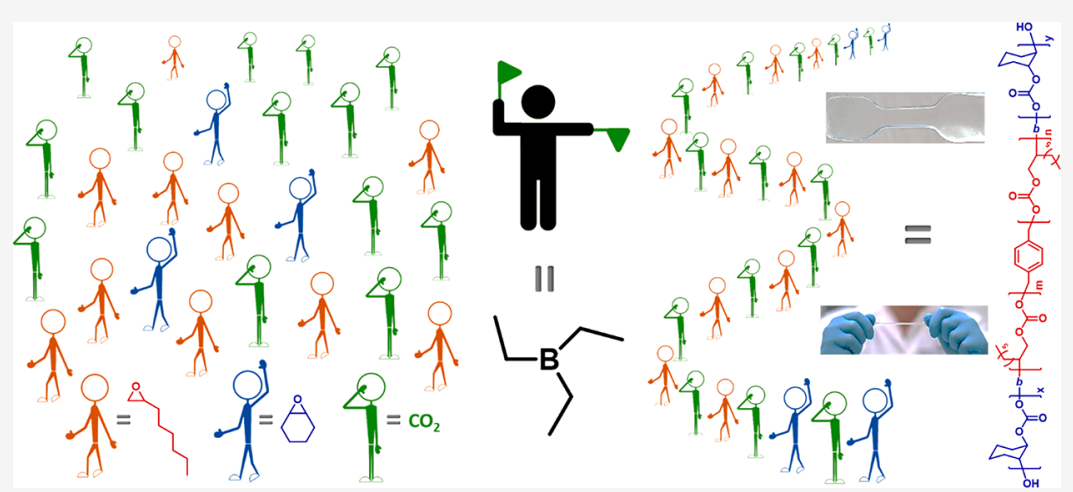

ABSTRACT: Various oxirane monomers including alkyl ether or allyl-substituted ones such as 1-butene oxide, 1-hexene oxide, 1octene oxide, butyl glycidyl ether, allyl glycidyl ether, and 2-ethylhexyl glycidyl ether were anionically copolymerized with $\mathrm{CO}_{2}$ into polycarbonates using onium salts as initiator in the presence of triethylborane. All copolymerizations exhibited a "living" character, and the monomer consumption was monitored by in situ Fourier-transform infrared spectroscopy. The various polycarbonate samples obtained were characterized by ${ }^{1} \mathrm{H}$ NMR, GPC, and differential scanning calorimetry. In a second step, all-polycarbonate triblock copolymers demonstrating elastomeric behavior were obtained in one pot by sequential copolymerization of $\mathrm{CO}_{2}$ with two different epoxides, using a difunctional initiator. 1-Octene oxide was first copolymerized with $\mathrm{CO}_{2}$ to form the central soft poly(octene carbonate) block which was flanked by two external rigid poly(cyclohexene carbonate) blocks obtained through subsequent copolymerization of cyclohexene oxide with $\mathrm{CO}_{2}$. Upon varying the ratio of 1-octene oxide to cyclohexene oxide and their respective ratios to the initiator, three all-polycarbonate triblock samples were prepared with molar masses of about $350 \mathrm{~kg} / \mathrm{mol}$ and 22,26 , and $29 \mathrm{~mol} \%$ hard block content, respectively. The resulting triblock copolymers were analyzed using ${ }^{1} \mathrm{H}$ NMR, GPC, thermogravimetric analysis, differential scanning calorimetry, and atomic force microscopy. All three samples demonstrated typical elastomeric behavior characterized by a high elongation at break and ultimate tensile strength in the same range as those of other natural and synthetic rubbers, in particular those used in applications such as tissue engineering.

\section{INTRODUCTION}

The copolymerization of $\mathrm{CO}_{2}$ with epoxides has received extensive attention as it allows one to transform a naturally abundant $\mathrm{C} 1$ resource, namely $\mathrm{CO}_{2}$, which is also a greenhouse gas, into degradable polymeric materials. ${ }^{1-3}$ Since its discovery in the $1969,{ }^{4}$ significant progress has been made mainly during the past two decades in terms of activity and selectivity of the catalysts developed. Heterogeneous catalysts include zinc glutarate (ZnGA) or carboxylates $(\mathrm{ZnCA})$, double metal cyanides (DMC), as well as rare earth metal ternary catalysts; on the other hand homogeneous catalysts are based on first row transition metals such as $\mathrm{Cr}$, $\mathrm{Co}, \mathrm{Zn}, \mathrm{Fe}$, or earth abundant metals such as $\mathrm{Al}, \mathrm{Mg}$, etc. associated with different ligands. ${ }^{3,5-10}$ Although numerous catalysts have been developed over time, none of them was actually designed to allow the copolymerization of $\mathrm{CO}_{2}$ indiscriminately with all epoxides available; either the metal or the ligand had to be modified specifically depending upon the epoxides chosen. Kim et al. first screened the activity of heterogeneous $\mathrm{Zn}-\mathrm{Co}(\mathrm{III})$ DMC catalyst for the copoly-

Received: May 5, 2020

Revised: June 8, 2020 
Scheme 1. Selected Epoxide Monomers for the Copolymerization with $\mathrm{CO}_{2}$ in the Presence of TEB

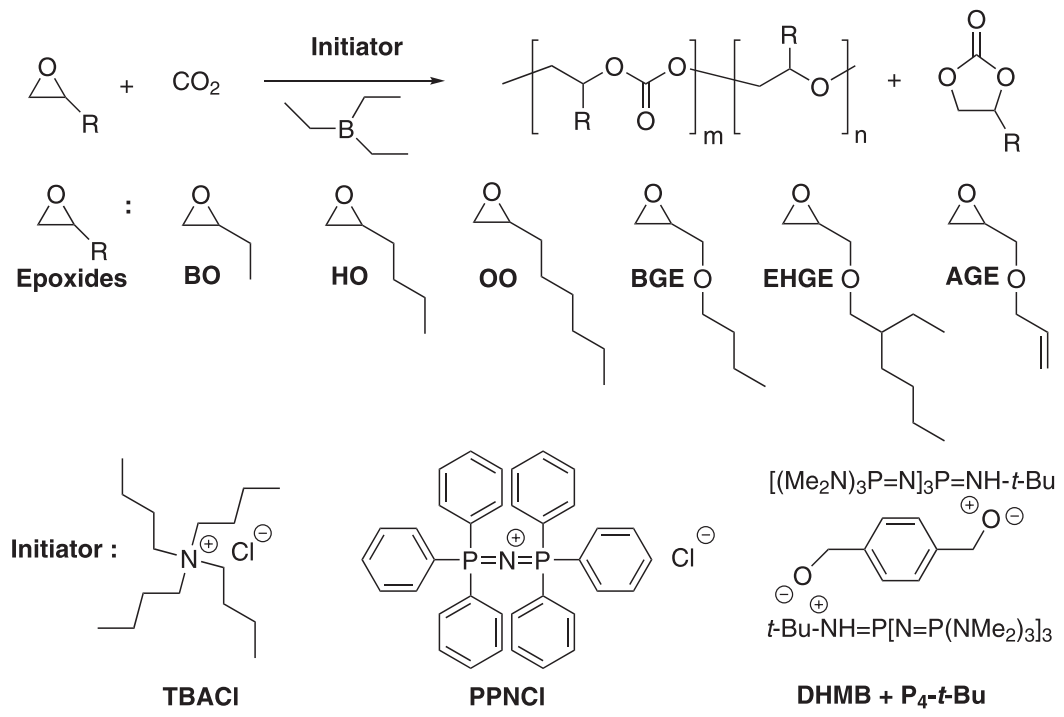

Scheme 2. Synthesis of PCHC-b-POC-b-PCHC Triblock Polycarbonate Copolymers

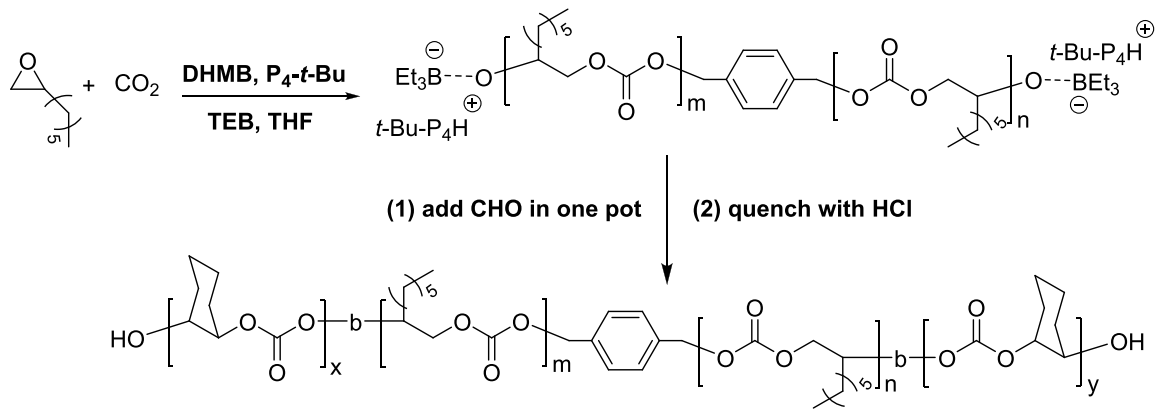

poly(cyclohexene carbonate-b-octene carbonate-b-cyclohexene carbonate)

merization of $\mathrm{CO}_{2}$ with epoxides carrying alkyl and alkoxymethyl substituents; they found no activity for epoxides with long substituted chain such as 1-hexene oxide (HO) and 1-octene oxide (OO). For others, they obtained polycarbonates with high ether contents. ${ }^{11}$ Zhang et al. on the other hand utilized the same heterogeneous $\mathrm{Zn}-\mathrm{Co}$ (III) DMC catalyst to investigate the copolymerization behavior of $\mathrm{CO}_{2}$ with alkyl-substituted epoxides; the polycarbonates obtained in the latter case exhibited $>90 \%$ of carbonate content but for epoxides such as ethylene oxide (EO) and propylene oxide (PO), the carbonate content in poly(ethylene carbonate) (PEC) and poly(propylene carbonate) (PPC) dropped to $55 \%$ and $73 \%$, respectively. ${ }^{12}$

Recently, our group reported the successful anionic copolymerization of $\mathrm{CO}_{2}$ with $\mathrm{PO}$ and cyclohexene oxide $(\mathrm{CHO})$ in the presence of triethylborane (TEB) and demonstrated that alternative polycarbonates could be synthesized under metal-free conditions. ${ }^{13-15}$ Since then, other epoxides such as glycidyl azide (GA) reported by us ${ }^{16}$ and phenyl glycidyl ether (PGE) and styrene oxide (SO) reported by Zhang et al. ${ }^{17}$ were also copolymerized with $\mathrm{CO}_{2}$ in the presence of TEB under conditions very similar to our first disclosure. In contrast to catalytic systems based on transition metals, the copolymerization of $\mathrm{CO}_{2}$ with epoxides mediated by TEB was achieved through a classical anionic ring-opening mechanism, allowing the synthesis of well-defined polycarbonates with controlled molar masses and structures, thus placing the latter system as an efficient and reliable tool of macromolecular engineering.

To harness the possibilities offered by this chemistry and exploit the versatility of TEB-mediated copolymerization of $\mathrm{CO}_{2}$ with epoxides, some commercially available epoxides including alkyl-substituted or alkoxymethyl-substituted ones such as 1-butene oxide (BO), $\mathrm{HO}, \mathrm{OO}$, butyl glycidyl ether (BGE), and 2-ethylhexyl glycidyl ether (EHGE) as well as a functional epoxide allyl glycidyl ether (AGE) were copolymerized with $\mathrm{CO}_{2}$ under the same conditions as for $\mathrm{PO}$ and $\mathrm{CHO}$. In the literature the copolymerization of $\mathrm{BO}, \mathrm{HO}$, and $\mathrm{OO}$ with $\mathrm{CO}_{2}$ using DMC catalysts has been described; ${ }^{11,12}$ on the other hand, ZnGA, ${ }^{18-20} \mathrm{Co}$ (III) salen complex, ${ }^{21-23}$ and rare earth metal catalysts ${ }^{24}$ were used to catalyze the copolymerization of $\mathrm{AGE}^{18,19,21,22}$ and $\mathrm{BGE}^{20,23,24}$ with $\mathrm{CO}_{2}$. In this work, we wish to demonstrate that the TEB-mediated system designed for the copolymerization of $\mathrm{PO}$ or $\mathrm{CHO}$ with $\mathrm{CO}_{2}$ is versatile enough to be applied to the above cited epoxides: we thus systematically investigated their copolymerization with $\mathrm{CO}_{2}$ in the presence of TEB using onium salts as initiator (Scheme 1 ).

In a second step taking advantage of our TEB-based copolymerization system, we synthesized in one-pot three samples of all-polycarbonate triblock ABA copolymer (Scheme 2) from a difunctional initiator, using $O O$ as the first epoxide to copolymerize with $\mathrm{CO}_{2}$ followed by $\mathrm{CHO}$. This sequential block copolymerization afforded triblock copolymers made of a 
Table 1. Copolymerization Data of $\mathrm{CO}_{2}$ with Various Epoxides Using TEB as Catalyst ${ }^{a}$

\begin{tabular}{|c|c|c|c|c|c|c|c|c|c|c|c|}
\hline entry & epoxide & initiator & TEB eq & $\mathrm{M} / \mathrm{I}$ & yield $(\%)^{b}$ & $\operatorname{PPC}(\%)^{c}$ & selectivity $(\%)^{d}$ & $M_{\mathrm{n}(\text { theo })}\left(10^{3}\right)^{e}$ & $M_{\mathrm{n}(\mathrm{GPC})}\left(10^{3}\right)$ & $\boxplus$ & $T_{\mathrm{g}} /{ }^{\circ} \mathrm{C}$ (DSC) \\
\hline 1 & $\mathrm{BO}$ & $\mathrm{TBACl}$ & 2 & 500 & 53 & 99 & 89 & 31 & 36 & 1.1 & - \\
\hline 2 & $\mathrm{BO}$ & $\mathrm{TBACl}$ & 3 & 500 & 62 & 99 & 94 & 36 & 43 & 1.1 & - \\
\hline 3 & BO & TBACl & 3 & 1000 & 50 & 99 & 90 & 58 & 55 & 1.1 & 15 \\
\hline 4 & $\mathrm{HO}$ & TBACl & 3 & 500 & 61 & 98 & 97 & 44 & 38 & 1.1 & - \\
\hline 5 & $\mathrm{OO}$ & TBACl & 3 & 500 & 58 & 99 & 93 & 50 & 48 & 1.1 & -23 \\
\hline 6 & BGE & $\mathrm{TBACl}$ & 3 & 500 & 43 & 99 & 86 & 37 & 30 & 1.1 & - \\
\hline 7 & EHGE & $\mathrm{TBACl}$ & 3 & 500 & 59 & 99 & 84 & 68 & 46 & 1.1 & - \\
\hline 8 & AGE & TBACl & 3 & 500 & 52 & 99 & 81 & 41 & 39 & 1.3 & - \\
\hline 9 & $\mathrm{HO}$ & $\mathrm{PPNCl}$ & 3 & 500 & 67 & 95 & 96 & 48 & 42 & 1.1 & - \\
\hline 10 & $\mathrm{HO}$ & $\mathrm{PPNCl}$ & 3 & 1000 & 45 & 99 & 88 & 65 & 54 & 1.1 & -5 \\
\hline 11 & $\mathrm{OO}$ & $\mathrm{PPNCl}$ & 3 & 1000 & 38 & 99 & 88 & 65 & 48 & 1.2 & - \\
\hline 12 & BGE & PPNCl & 3 & 1000 & 33 & 99 & 88 & 57 & 58 & 1.2 & -22 \\
\hline 13 & EHGE & $\mathrm{PPNCl}$ & 3 & 750 & 53 & 99 & 94 & 91 & 55 & 1.1 & - \\
\hline 14 & AGE & $\mathrm{PPNCl}$ & 3 & 750 & 33 & 99 & 78 & 39 & 36 & 1.2 & - \\
\hline 15 & AGE & $\mathrm{PPNCl}$ & 4 & 750 & 44 & 99 & 91 & 52 & 45 & 1.3 & -12 \\
\hline 16 & $\mathrm{HO}$ & DHMB & 3 & 1500 & 70 & 95 & 99 & 151 & 105 & 1.2 & - \\
\hline 17 & $\mathrm{OO}$ & DHMB & 3 & 2000 & 47 & 98 & 99 & 162 & 152 & 1.2 & -24 \\
\hline 18 & BGE & DHMB & 3 & 2000 & 36 & 97 & 99 & 125 & 109 & 1.1 & -23 \\
\hline 19 & EHGE & DHMB & 3 & 1500 & 67 & 98 & 95 & 231 & 137 & 1.2 & -46 \\
\hline
\end{tabular}

${ }^{a}$ All reactions have been conducted at $60{ }^{\circ} \mathrm{C}$ under 10 bar of $\mathrm{CO}_{2}$ pressure for $12 \mathrm{~h} .{ }^{b}$ Yield = weight of polymer obtained/theoretical weight of polymer at full conversion $\times 100 \% .{ }^{c} \mathrm{PPC}=$ percent of polycarbonate content, calculated from ${ }^{1} \mathrm{H}$ NMR of purified polymers. ${ }^{d}$ Selectivity $=$ percent of linear polymer versus all the products including cyclic polycarbonates, calculated from ${ }^{1} \mathrm{H}$ NMR of crude products. ${ }^{e}$ Theoretical molar mass $=$ $\left(M_{\text {epoxide }}+44\right) \times \mathrm{DP}_{\text {targeted }} \times$ yield.

soft central poly(octene carbonate) (POC) block flanked by two hard poly(cyclohexene carbonate) (PCHC) blocks. The targeted molar masses of the PCHC- $b$-POC- $b$-PCHC triblock copolymers were relatively high, almost $300 \mathrm{~kg} / \mathrm{mol}$ for the POC soft central block only; such high molar masses were aimed to facilitate a microphase separation between POC $\left(T_{\mathrm{g}}\right.$, $\left.-24{ }^{\circ} \mathrm{C}\right)$ and PCHC $\left(T_{\mathrm{g}}, 120^{\circ} \mathrm{C}\right)$ blocks and to eventually obtain either spherical or cylindrical morphologies with glassy $\mathrm{PCHC}$ spheres or cylinders dispersed in a continuous rubbery POC matrix. Samples exhibiting such morphologies and corresponding to a physical network of flexible chains indeed exhibit elastomeric behavior. To the best of our knowledge, this is the first report on all-polycarbonate thermoplastic elastomers (TPE) obtained in addition under metal-free conditions. Besides the microphase separation other factors play an important role in the thermomechanical behavior of TPEs. For instance, the presence of trapped entanglements in the soft central block is also known to influence the tensile strength of TPEs. Because of the modest contribution of entanglements these all-polycarbonate triblock copolymers showed the typical behavior of soft rubbers characterized by moderate Young's moduli and high elongations prior to failure. Such materials would be appropriate for applications in tissue engineering which require similar characteristics.

\section{RESULTS AND DISCUSSION}

Before attempting to synthesize all-polycarbonate triblock copolymers exhibiting some of the essential features of TPEs found for instance in SIS or SBS copolymers, we first established the conditions to obtain well-defined polycarbonate homopolymers by copolymerizing various epoxides with $\mathrm{CO}_{2}$.

Copolymerization of $\mathrm{CO}_{2}$ with a Wide Range of Epoxides. From the literature published so far on TEBmediated synthesis of polycarbonates it appears that the success of the copolymerization of epoxides with $\mathrm{CO}_{2}$ depends on the amount of TEB needed, which varies with the epoxides considered. For instance, polycarbonate samples with high carbonate content and high linear versus cyclic selectivity require a ratio of TEB to the anionic initiator that can vary from 2 for $\mathrm{PO},{ }^{13,25}$ to 3,6 , and 8 for GA, ${ }^{16} \mathrm{PGE}$, and $\mathrm{SO},{ }^{17}$ respectively. $\mathrm{BO}$ which carries one additional carbon to $\mathrm{PO}$ was copolymerized with $\mathrm{CO}_{2}$ under reaction conditions similar to those of $\mathrm{PO} ; 2$ equiv of TEB were thus used with respect to the anionic initiator, $\mathrm{TBACl}$, at $60^{\circ} \mathrm{C}$ under $10 \mathrm{bar}$ of $\mathrm{CO}_{2}$. An alternating poly(butylene carbonate) (PBC) sample was obtained with a selectivity of $89 \%$ of linear versus cyclic carbonates (entry 1, Table 1), which is slightly lower than those observed in the case of PO. ${ }^{25}$ The steric hindrance due to the ethyl substituent of the epoxide ring indeed slightly decreased the reactivity of $\mathrm{BO}$ which in turn favored the formation of cyclic carbonate structure. Upon utilizing more TEB to activate further $\mathrm{BO}$, propagation could be favored over backbiting; with 3 equiv of TEB with respect to TBACl, both the linear versus cyclic selectivity and the overall yield could be improved, and yet an alternating structure could be retained in the polycarbonate formed (entry 2, Table 1, Figure S1). When targeting a DP of 1000 instead of 500, the same conditions afforded an alternating PBC sample of $55 \mathrm{~kg} / \mathrm{mol}$ molar mass. This is close to the expected value, and the selectivity slightly decreased to $90 \%$ (entry 3, Table 1).

The same reaction conditions (3 equiv of TEB to the initiator $\mathrm{TBACl}$ ) were then applied to the copolymerization of $\mathrm{CO}_{2}$ with other epoxides (entries 4-8, Table 1). For comparison purpose, all copolymerizations were terminated after $12 \mathrm{~h}$ of reaction. In all cases, the polycarbonates obtained were alternating with negligible polyether linkages (Figure S2S5). The linear versus cyclic selectivity decreased from $97 \%$ to $81 \%$ in the following order of $\mathrm{HO}>\mathrm{OO}>\mathrm{BGE}>\mathrm{EHGE}>$ AGE. Besides the steric hindrance of substituents which can affect the monomer reactivity as shown in the case of $\mathrm{BO}, \mathrm{HO}$, and $\mathrm{OO}$, the presence of an oxygen atom in addition to the 

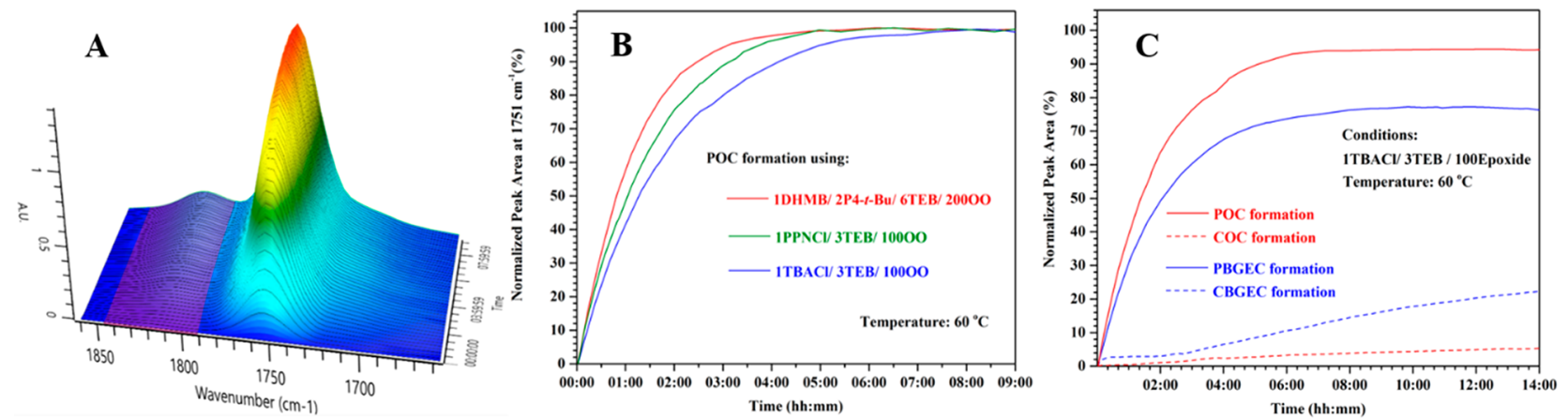

Figure 1. In situ FTIR study: (A) a representative surface image showing the evolving peaks at 1811 and $1751 \mathrm{~cm}^{-1}$; (B) polycarbonate formation curves using different initiators to copolymerize $\mathrm{OO}$ and $\mathrm{CO}_{2}$; and $(\mathrm{C})$ polycarbonate and cyclic carbonate formation curves for $\mathrm{OO}$ and $\mathrm{BGE}$ using TBACl as initiator.

one that is part of the epoxide ring can explain the lower reactivity of BGE, EHGE, and AGE. Indeed the oxygen of the epoxide substituent can compete with the one of the ring for interaction with TEB which in turn lowers the monomer reactivity, the polymerization yield, and favors a high cyclic content. When comparing OO with BGE which carries a substituent of similar length with six atom spacers, the lower selectivity of BGE (87\%) with respect to that of OO (93\%) can be accounted by the interactions of its substituent oxygen with TEB. The interactions between TEB and the oxygen carried by BGE and EHGE side groups could be characterized by ${ }^{1} \mathrm{H}$ NMR. Inside Young's NMR tubes, these two epoxides were respectively mixed in $\mathrm{CDCl}_{3}$ with one equal equivalent of TEB ( $1 \mathrm{M}$ in THF). In a separate tube containing the same amount of THF, the two same epoxides were respectively charged without TEB for comparison purposes. The signal at around $3.30 \mathrm{ppm}$ corresponding to the methylene proton adjacent to the ether oxygen shifted toward the low-field region in both cases of BGE and EHGE (Figure S6A). It is noteworthy that the change in chemical shift $(0.0016 \mathrm{ppm})$ for BGE was larger than that (0.0006 ppm) for EHGE, indicating a stronger interaction between the ether oxygen of BGE and TEB than with the oxygen carried by EHGE. The higher steric hindrance due to the branched structure of its alkyl substituent makes TEB less accessible to the oxygen carried by EHGE, which results in a weaker interaction. This observation can explain the higher rate of polymerization and yield of poly(2-ethylhexyl glycidyl ether carbonate) (PEHGEC, $59 \%$ ) compared to that of poly(butyl glycidyl ether carbonate) (PBGEC, 43\%), the steric hindrance around its ether oxygen warranting a strong interaction of TEB with the epoxide ring oxygen and thus a stronger activation. Such competitive interactions between different sites of the epoxide monomers are exemplified in the case of AGE, which is characterized by a lower rate of polymerization and a lower linear versus cyclic selectivity compared to those of $\mathrm{OO}$ which carries only one site of interaction with TEB. In the AGE case, besides its interaction with ether oxygen, TEB can interact with its double bonds, which is reminiscent of the hydroboration reaction of alkenes. We could clearly identify three kinds of interactions between AGE and TEB through ${ }^{1} \mathrm{H}$ NMR characterization. Upon using 4 equiv of TEB with respect to AGE, the signals due to the protons on the epoxide ring, those adjacent to the ether oxygen, as well as those characteristic of double bond shifted toward the low-field region as a result of their interactions with TEB: the change in chemical shift value were $0.0020,0.0034$, and $0.0010 \mathrm{ppm}$, respectively (Figure
S6B). When high degree of polymerizations (DP) were targeted with AGE, a lower linear versus cyclic selectivity was observed as well as a low yield and high molar mass polycarbonates could not be obtained.

Because of its bulkier cation than that of $\mathrm{TBACl}, \mathrm{PPNCl}$ was tried as initiator with the expectation that the ate complex formed with TEB will favor a higher rate of copolymerization with $\mathrm{CO}_{2}$ (entries 9-14, Table 1). Indeed, upon using PPNCl as the initiator and targeting DP up to 1000 , the copolymerization of $\mathrm{CO}_{2}$ with various epoxides afforded high molar mass polycarbonates with around $90 \%$ of linear versus cyclic selectivity and moderate yield after $12 \mathrm{~h}$ of reaction. In the case of AGE, more TEB (4 equiv) had to be added to improve its rate of copolymerization and its selectivity (entry 15, Table 1).

Such a trend could be confirmed upon using an initiator with a much bulkier cation such as phosphazenium. Upon deprotonation of DHMB diol with a phosphazene base such as $\mathrm{P}_{4}-t-\mathrm{Bu}$, the copolymerization of $\mathrm{CO}_{2}$ with epoxides exhibited higher rate and afforded linear difunctional polycarbonates with excellent selectivity (entries 17-19, Table 1). Special care should be given to the order of introducing both epoxides and $\mathrm{CO}_{2}$ as the alkoxide-TEB ate complex associated with a phosphazenium cation and TEB initiates at once the ring opening polymerization of epoxides and brings about a fast propagation. It is indeed indispensable to introduce the epoxide in a reactor already filled with $\mathrm{CO}_{2}$ or place a separate vial filled with the epoxide in the reactor and subsequently break it to free the latter monomer. As shown in Table 1, all polycarbonates produced under those conditions and through this system exhibit carbonate contents higher than $95 \%$.

The copolymerization of epoxides with $\mathrm{CO}_{2}$ in the presence of TEB using different initiators was monitored using in situ FTIR. Figure 1A shows the evolution of two adsorption peaks at 1811 and $1751 \mathrm{~cm}^{-1}$ which correspond to the formation of cyclic carbonates and that of polycarbonate, respectively. To compare the polymerization rates using different initiators, we monitored the copolymerization of $\mathrm{OO}$ with $\mathrm{CO}_{2}$ using $\mathrm{PPNCl}, \mathrm{TBACl}$, and $\mathrm{DHMB} / \mathrm{P}_{4}-\mathrm{t}-\mathrm{Bu}$ as initiator, respectively. The initial concentrations of OO and TEB as well as the $\mathrm{CO}_{2}$ pressure were the same in all cases with a targeted DP of 100 for each initiating site. As can be seen in Figure 1B, the rates of polycarbonate formation using different initiators can be ranked in the following order: $\mathrm{DHMB} / \mathrm{P}_{4}-\mathrm{t}-\mathrm{Bu}>\mathrm{PPNCl}>$ $\mathrm{TBACl}$, confirming the fact that the copolymerization rate increased upon increasing the steric hindrance of the cations. 
Table 2. Characterization Data for POC Middle Block and PCHC-b-POC-b-PCHC Triblocks

\begin{tabular}{lcccccccccc}
\multicolumn{1}{c}{ polymer } & $\mathrm{CHC}$ mol \% & $\mathrm{PCHC}$ wt \% & $\mathrm{CO}_{2} \mathrm{wt} \%$ & $M_{\mathrm{n}}{ }^{a}\left(10^{3}\right)$ & $D^{a}$ & $T_{\mathrm{g}}{ }^{b}\left({ }^{\circ} \mathrm{C}\right)$ & $T_{10 \%}{ }^{c}\left({ }^{\circ} \mathrm{C}\right)$ & $\sigma_{\mathrm{m}}{ }^{d}(\mathrm{MPa})$ & $\varepsilon_{\mathrm{b}}{ }^{d} \%$ & $E^{e}(\mathrm{MPa})$ \\
$\mathrm{POC}$ & 0 & 0 & 26 & 280 & 1.2 & -24 & 206 & - & - \\
$\mathrm{P}(\mathrm{C}-\mathrm{O}-\mathrm{C})_{1}$ & 22 & 19 & 27 & 353 & 1.3 & $-20,107$ & 235 & $2.04 \pm 0.09$ & $1052 \pm 71$ & $1.43 \pm 0.11$ \\
$\mathrm{P}(\mathrm{C}-\mathrm{O}-\mathrm{C})_{2}$ & 26 & 22 & 27 & 363 & 1.3 & $-19,119$ & 243 & $2.76 \pm 0.07$ & $331 \pm 4$ \\
$\mathrm{P}(\mathrm{C}-\mathrm{O}-\mathrm{C})_{3}$ & 29 & 25 & 27 & 372 & 1.4 & $-19,119$ & 243 & $3.24 \pm 0.02$ & $454 \pm 29$ & $2.43 \pm 0.11$
\end{tabular}

${ }^{a}$ Determined by GPC using THF as the solvent and polystyrene standard. ${ }^{b}$ Determined from the second scan of DSC curves (heating rate: $10{ }^{\circ} \mathrm{C} /$ min). ${ }^{c}$ Determined by TGA under $\mathrm{N}_{2}$ atmosphere with a heating rate of $10^{\circ} \mathrm{C} / \mathrm{min} .{ }^{d}$ Ultimate tensile strength $\left(\sigma_{\mathrm{m}}\right)$ and elongation at break $\left(\varepsilon_{\mathrm{b}}\right)$ determined from stress-strain curves with the tensile rate being $50 \mathrm{~mm} / \mathrm{min}$. ${ }^{e}$ Young's modulus determined from the slope of a fitted line in the stress-strain curve within the initial strain $(<1 \%)$.

To carry out the copolymerization of $\mathrm{CO}_{2}$ with various epoxides at a same epoxide concentration is a challenge since the latter differ by their molar masses and densities and also because of the coordinating property of THF; since the amount of THF used can indeed vary from one epoxide to another this can in turn affect the rate of reaction. Therefore, we only compared the reactivity of $\mathrm{OO}$ with that of BGE which have similar molar masses (128.2 vs 130.2$)$ and density ( 0.84 vs 0.91$)$ using $\mathrm{TBACl}$ as the initiator. It can be seen in Figure $1 \mathrm{C}$ that the rate of POC formation is higher than that of PBGEC, confirming the higher reactivity of $O O$ with respect to that of BGE due to the competing interaction of TEB with the two oxygen atoms of BGE. Accordingly the linear versus cyclic selectivity for $\mathrm{OO}$ is higher than that for $\mathrm{BGE}$ as a larger portion of cyclic butyl glycidyl ether carbonate (CBGEC) than that of cyclic octene carbonate (COC) was generated. It is noteworthy that the rate of formation of cyclic carbonate was not constant during the reaction. It increased dramatically after about $50 \%$ conversion, indicating that cyclic carbonates were formed in a later stage of copolymerization when less monomer was available for copolymerization.

Then the various polycarbonates prepared were analyzed by DSC (Figure S7-S14). As the size of the epoxide substituents increases, $T_{\mathrm{g}}$ values of corresponding polycarbonates decrease accordingly. The $T_{\mathrm{g}}$ values of $\mathrm{PBC}$, poly(1-hexene carbonate) (PHC), and POC with similar molar mass conform to the following order: $15,-5$, and $-23{ }^{\circ} \mathrm{C}$ (Table 1, Figure S6-S9). Those values are higher than the reported ones $(6,-18$, and $-27{ }^{\circ} \mathrm{C}$ ) because of the alternating structure of the polycarbonates synthesized using TEB. ${ }^{12}$ PBGEC displayed a $T_{\mathrm{g}}$ of $-23{ }^{\circ} \mathrm{C}$ (Figure S11) of the same order as that of POC, indicating that the pendant ether function have no effect on the $T_{\mathrm{g}}$ of the corresponding polycarbonate. Poly(ally glycidyl carbonate) (PAGEC) exhibited a higher $T_{\mathrm{g}}$ of $-12{ }^{\circ} \mathrm{C}$, probably resulting from the higher rigidity of the double bond it carries. PEHGEC however exhibited a lower $T_{\mathrm{g}}$ of $-46{ }^{\circ} \mathrm{C}$ (Figure S13) likely due to its branched alkyl substituent compared to the reported value of $-38{ }^{\circ} \mathrm{C}$ for poly(dodecene carbonate $)^{12}$ with its 10 -carbon substituent.

Synthesis of PCHC-b-POC- $b$-PCHC All-Polycarbonate Triblock Copolymers. Using $\mathrm{Zn}$ (II) diiminate as a catalyst, Coates et al. synthesized multiblock functionalized PCHC copolymers from $\mathrm{CHO}$ and functionalized $\mathrm{CHOs}$ carrying different functional substituents at the 4-position of the cyclohexane ring. ${ }^{26}$ Through one-pot/two-step strategy, Darensbourg, ${ }^{27,28}$ Nozaki, ${ }^{29,30} \mathrm{Lu}^{31}$ and their co-workers reported the synthesis of polycarbonate diblock copolymers using salencomplexes based on cobalt or chromium; when water was used as a chain transfer agent, polycarbonate triblock copolymers could be obtained. ${ }^{27,28}$ On the other hand, through TEBmediated anionic copolymerization of $\mathrm{CO}_{2}$ with sequentially added epoxides such as $\mathrm{PO}$ and $\mathrm{CHO}$, polycarbonate diblock copolymers could be generated. ${ }^{25}$ Here our objective is to synthesize all-polycarbonate triblock ABA-type copolymers featuring a central soft POC block $\left(T_{\mathrm{g}}=-24{ }^{\circ} \mathrm{C}\right)$ flanked by two hard PCHC $\left(T_{\mathrm{g}}=120^{\circ} \mathrm{C}\right)$ blocks. On the model of SBS or SIS triblock copolymers, we expect the PCHC hard block to form rigid microdomains acting as physical cross-links that are linked one to another by the soft POC chains. Even though the two types of polycarbonates taken separately exhibit quite contrasted $T_{\mathrm{g}}$ values, the challenge here is to obtain phase separation between the two blocks. Phase separation in such materials is indeed an essential factor to impart the resulting triblock polycarbonate with elasticity and tensile modulus typical of TPEs on the one hand and stretchability and long strains due to the soft blocks on the other.

Phase separation being indispensable in such copolymers for the very manifestation of their elastic character, the first requirement to ensure is that the two types of polycarbonate blocks in the copolymer are pure enough and do not tamper one another. The second requirement to obtain a strongly segregated system in such block copolymers is to secure a value of $\chi N$ much higher than 10.5, $\chi$ being the Flory-Huggins or interaction parameter and $N$ the degree of polymerization. As the two types of blocks are polycarbonates, the $\chi$ parameter is certainly low due to the compatibility between the two blocks; the only means to achieve phase separation in such triblock copolymers is to target the synthesis of polycarbonate blocks of large size, thus of high $N$. One example of triblock copolymers PCHC- $b$-PAGEC- $b$-PCHC synthesized in the presence of water showed that no microphase separation was observed. ${ }^{32}$

Since the TEB-mediated synthesis of polycarbonate by anionic polymerization suffers from only backbiting as side reactions, the risk of contamination of the $A B A$ triblock grown from difunctional initiator by $\mathrm{AB}$ diblocks is insignificant. To get extremely high molar mass of polycarbonates, the copolymerization must be carried out under super dry conditions, as even a trace of water, for instance present in $\mathrm{CO}_{2}$, can initiate polymerization and produce polycarbonates of lower than expected molar masses. ${ }^{13}$ We addressed this problem recently and found that the solution was to dry $\mathrm{CO}_{2}$ with triisobutylaluminum (TiBA) through bubbling which warranted the synthesis of well-defined polycarbonates with molar mass up to $1 \mathrm{million} \mathrm{g} / \mathrm{mol}^{25}$ After drying thoroughly, the copolymerization of $\mathrm{CO}_{2}$ with $\mathrm{OO}$ was performed in the presence of TEB with $\mathrm{DHMB}$ as a difunctional initiator and $\mathrm{P}_{4}-t-\mathrm{Bu}$ as a cation associated with the growing boron-ate species. A linear difunctional POC soft block of low $T_{\mathrm{g}}$ was obtained as shown in Scheme 2. A full conversion of $\mathrm{OO}$ must be achieved before adding the second monomer, $\mathrm{CHO}$, to ensure that tapered ABA triblocks are not eventually obtained. Indeed such tapered block copolymers would not exhibit phase 

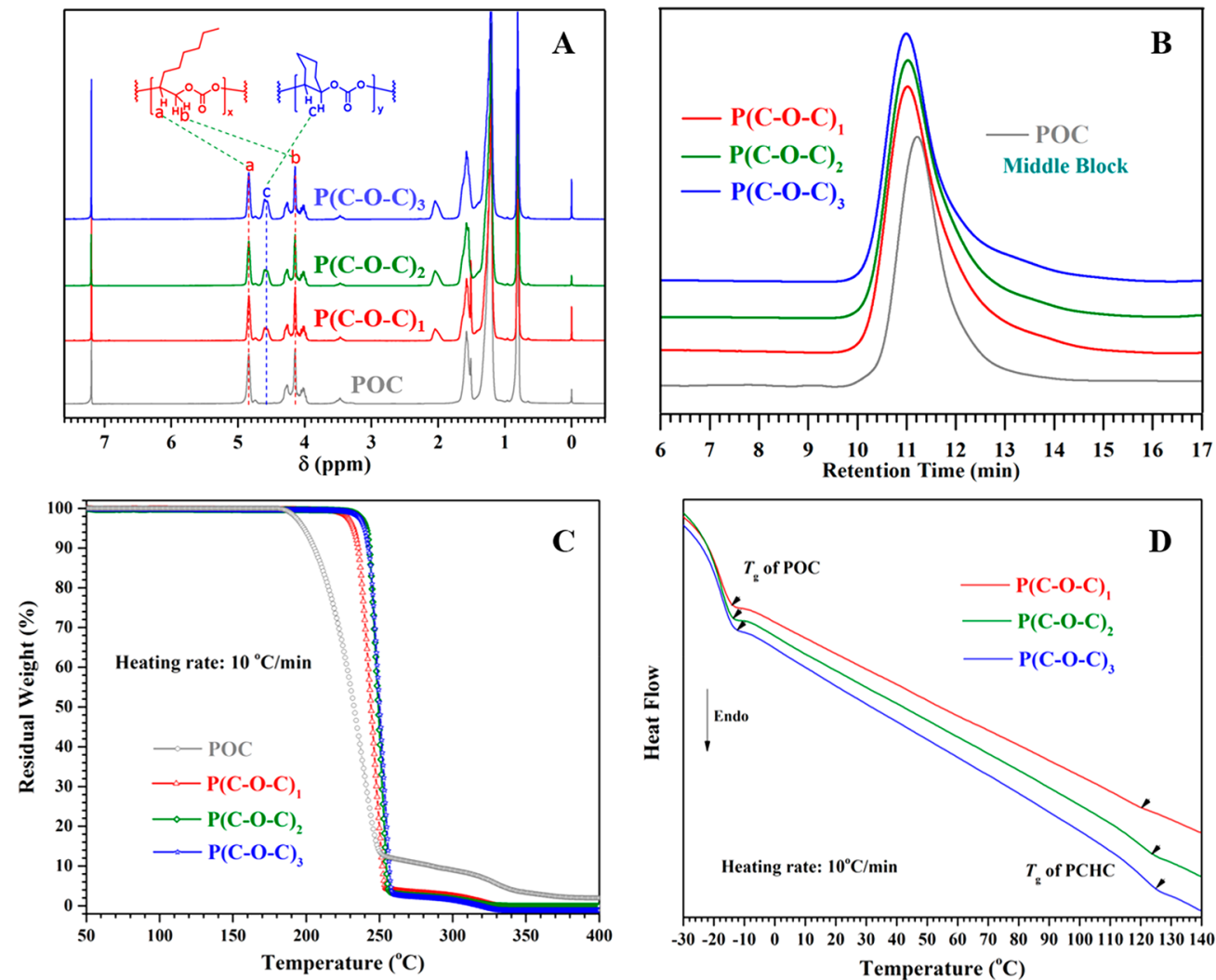

Figure 2. Characterization of the $\mathrm{CO}_{2}$-based polycarbonate triblock copolymers: (A) ${ }^{1} \mathrm{H}$ NMR $\left(\mathrm{CDCl}_{3}\right)$ spectra, (B) GPC (THF) traces, (C) TGA curves, and (D) DSC curves.

separation and the concomitant elastomeric mechanical performance. Then $\mathrm{CHO}$ was introduced in the reactor; to this end the latter was cooled down upon full consumption of $\mathrm{OO}$ without releasing $\mathrm{CO}_{2}$. By adjusting the amount of $\mathrm{CHO}$, three triblock $\mathrm{ABA}$ copolymers of different compositions, abbreviated as $\mathrm{P}(\mathrm{C}-\mathrm{O}-\mathrm{C})_{1}, \mathrm{P}(\mathrm{C}-\mathrm{O}-\mathrm{C})_{2}$, and $\mathrm{P}(\mathrm{C}-\mathrm{O}-\mathrm{C})_{3}$, were eventually obtained (Table 2 ).

The successful synthesis of the triblock copolymers could be confirmed by ${ }^{1} \mathrm{H}$ NMR spectra (Figure $2 \mathrm{~A}$ ). The peaks at 4.84 and $4.14 \mathrm{ppm}$ (peaks a, b) correspond to the protons of the backbone of the POC central block; another peak at around $4.58 \mathrm{ppm}$ (peak c) corresponding to the methine protons of the two external PCHC blocks can be seen after the formation of the triblock copolymers. The composition of the triblock copolymers made of PCHC and POC blocks could be calculated based on the intensity of the peaks a and c. The $\mathrm{PCHC}$ weight percent for $\mathrm{P}(\mathrm{C}-\mathrm{O}-\mathrm{C})_{1}, \mathrm{P}(\mathrm{C}-\mathrm{O}-\mathrm{C})_{2}$, and $\mathrm{P}(\mathrm{C}-\mathrm{O}-\mathrm{C})_{3}$ is $19 \%, 22 \%$, and $25 \%$, respectively. The $\mathrm{CO}_{2}$ weight percent in such triblock copolymers is equal to $27 \%$, which represents the highest $\mathrm{CO}_{2}$ content in $\mathrm{CO}_{2}$-based elastomers. Monomodal GPC traces were observed in all three cases of triblock samples. A clear shift toward the high molar mass region compared to the traces of the POC block precursor can be seen, indicating the successful growth of $\mathrm{PCHC}$ blocks and excluding the presence of any homo $\mathrm{PCHC}$ and of POC- $b$-PCHC diblock copolymers (Figure 2B). Prepared under strictly dried conditions, the triblock copolymer samples exhibit molar masses above $350 \mathrm{~kg} / \mathrm{mol}$ upon GPC characterization.

Thermal, Morphological, Rheological, and Mechanical Properties of PCHC- $b$-POC- $b$-PCHC Triblock Copolymers. The thermal stability of the triblock copolymers was evaluated by TGA tests. As can be seen in Figure 2C, the triblock copolymers undergo degradation between 200 and $250{ }^{\circ} \mathrm{C}$ which is typical of aliphatic polycarbonates. The degradation temperatures when $10 \%$ mass is lost $\left(T_{d 10 \%}\right)$ for $\mathrm{P}(\mathrm{C}-\mathrm{O}-\mathrm{C})_{1}, \mathrm{P}(\mathrm{C}-\mathrm{O}-\mathrm{C})_{2}$, and $\mathrm{P}(\mathrm{C}-\mathrm{O}-\mathrm{C})_{3}$ are 235,243 , and $243{ }^{\circ} \mathrm{C}$, respectively. However, the $T_{d 10 \%}$ value for the POC homopolymer is $206{ }^{\circ} \mathrm{C}$, indicating that the stability increases when POC is flanked by two hard blocks in a triblock copolymer structure. Raising the PCHC content increased the stability of the triblock copolymers which levels off after the PCHC content reaches $22 \%$. All three triblock copolymers produced no residues after being heated beyond $340{ }^{\circ} \mathrm{C}$.

The $T_{\mathrm{g}}$ values of the triblock copolymers were determined by DSC (Figure 2D). Two distinctive $T_{\mathrm{g}}$ values were detected for all three triblock samples, corroborating the occurrence of microphase separated triblock copolymers. The $T_{\mathrm{g}}$ values for the soft POC block in the three samples remained the same at around $-20{ }^{\circ} \mathrm{C}$, whereas the $T_{\mathrm{g}}$ values of the $\mathrm{PCHC}$ hard block increased from 107 to $119^{\circ} \mathrm{C}$ with their molar masses and their weight percentages. Compared to the $T_{\mathrm{g}}$ values of POC $\left(-24^{\circ} \mathrm{C}\right)$ and of PCHC $\left(120^{\circ} \mathrm{C}\right)$, some compatibility between the two blocks thus occurred. A stronger microphase separation occurred in the cases of $\mathrm{P}(\mathrm{C}-\mathrm{O}-\mathrm{C})_{2}$ and $\mathrm{P}(\mathrm{C}-$ $\mathrm{O}-\mathrm{C})_{3}$ which included more $\mathrm{PCHC}$.

The microphase separation was further confirmed by AFM. Due to their fully aliphatic nature, the polycarbonate triblock copolymers could not be stained selectively which is a prerequisite for electron microscopy. However, the visualization of the microphase separation of the synthesized thermoplastic elastomers could be accomplished by using AFM which could "sense" the variation of stiffness on a polymer surface. ${ }^{33}$ The domains formed by the soft block in 

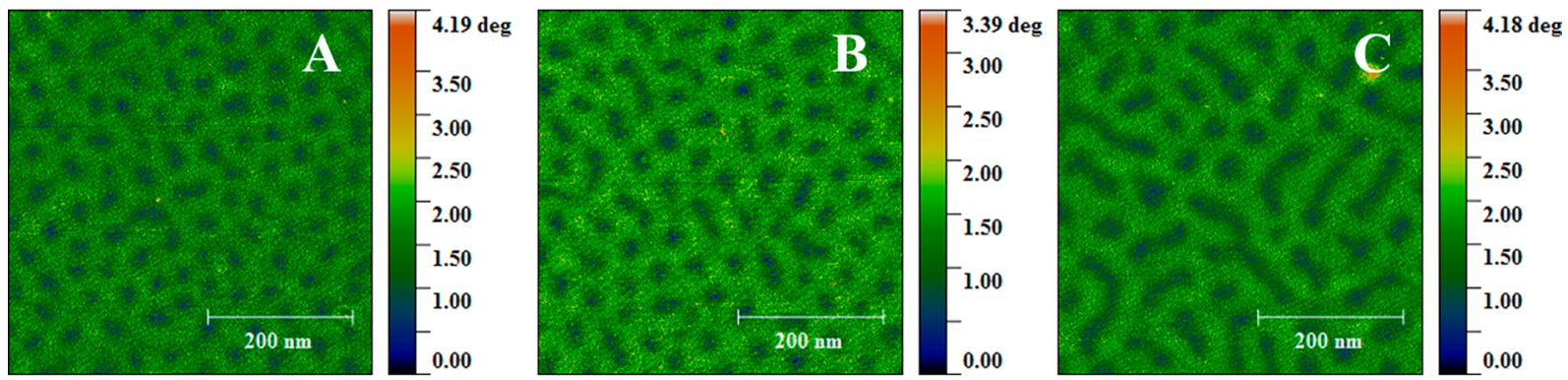

Figure 3. AFM phase images for $(\mathrm{A}) \mathrm{P}(\mathrm{C}-\mathrm{O}-\mathrm{C})_{1}$, (B) $\mathrm{P}(\mathrm{C}-\mathrm{O}-\mathrm{C})_{2}$, and $(\mathrm{C}) \mathrm{P}(\mathrm{C}-\mathrm{O}-\mathrm{C})_{3}$.
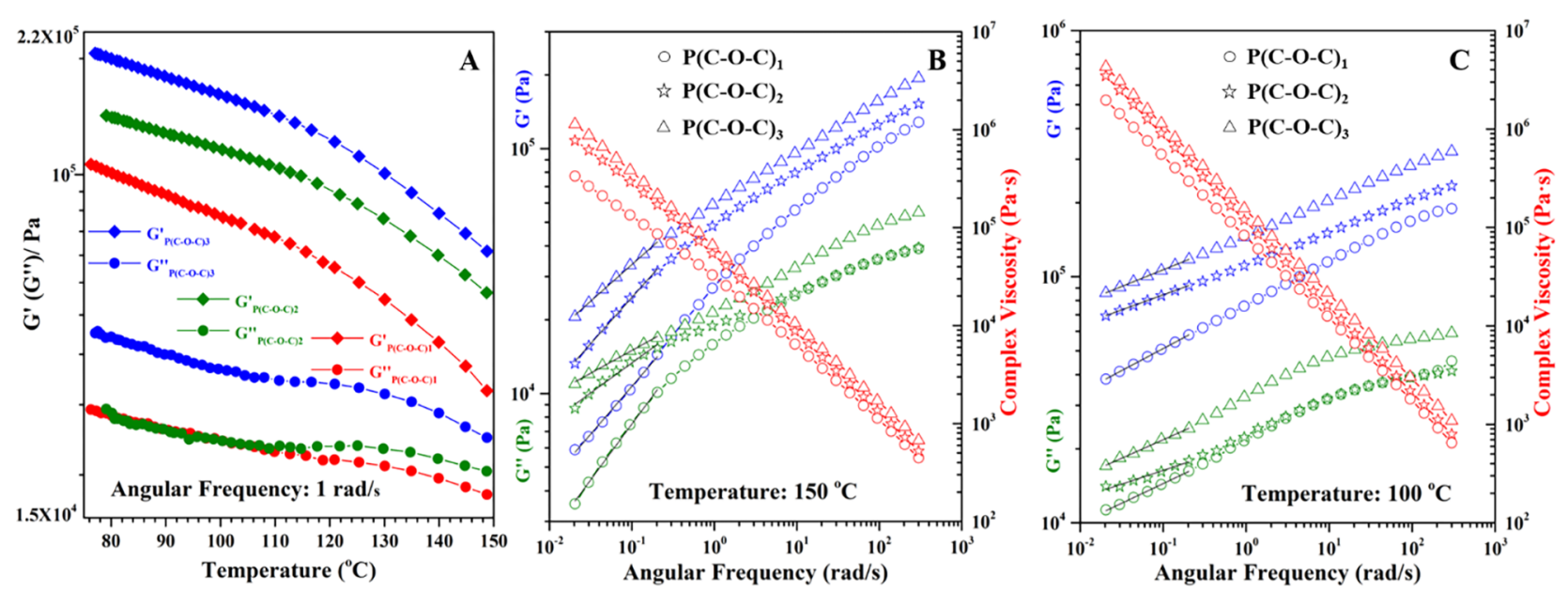

Figure 4. Rheological behaviors of PCHC- $b$-POC- $b$-PCHC triblock copolymers. (A) Logarithm of storage modulus $\left(G^{\prime}\right)$ and loss modulus $\left(G^{\prime \prime}\right)$ as a function of temperature ( $1 \%$ strain, $\left.1 \mathrm{rad} \mathrm{s}^{-1}\right)$; (B) viscoelastic behavior during frequency sweep conducted at a temperature of $150{ }^{\circ} \mathrm{C}$, and $(\mathrm{C})$ viscoelastic behavior during frequency sweep conducted at a temperature of $100{ }^{\circ} \mathrm{C}$.

such triblock copolymers exhibit a significant lower stiffness than that of the domains formed by the hard blocks, revealing the phase morphology using a tapping-mode AFM. We spincoated the three triblock copolymers solution in THF (2 wt \%) on silicon wafers coated with $\mathrm{SiO}_{2}$. Microphase separation occurred upon slow solvent evaporation. The phase images (Figure 3) clearly show microphase-separated structure with the dark domains being formed by the hard PCHC block dispersed in the continued soft block phases. By examining the morphology of the structures one can find that (1) the hard domains in $\mathrm{P}(\mathrm{C}-\mathrm{O}-\mathrm{C})_{1}$ are mostly spheres with an average diameter of $22 \mathrm{~nm}$; the hard domains in $\mathrm{P}(\mathrm{C}-\mathrm{O}-\mathrm{C})_{3}$ which has the highest content of PCHC blocks appear as cylinders, while those in $\mathrm{P}(\mathrm{C}-\mathrm{O}-\mathrm{C})_{2}$ are made of both spheres and small cylinders.

Considering the variation in the stiffness of the hard and soft block components in the synthesized block copolymers, as evident from the AFM phase images, the rheological response of these materials below and above the glass transition temperature of the hard block appears to us of specific interest. The viscoelastic properties of the PCHC- $b$-POC- $b$ $\mathrm{PCHC}$ triblock copolymers were thus investigated via rheology using plate-plate geometry. Figure $4 \mathrm{~A}$ exhibits the gradual decrease of the storage modulus $\left(G^{\prime}\right)$ and loss modulus $\left(G^{\prime \prime}\right)$ of the triblock copolymers containing 19,22 , and 25 wt \% hard block upon heating during a temperature ramp, at a specific frequency of $1 \mathrm{rad} / \mathrm{s}$. Each data point was recorded while slowly cooling. At $150{ }^{\circ} \mathrm{C}$ both the soft and hard block are above their respective glass transition temperatures. At approximately $120^{\circ} \mathrm{C}$, a change of slope in the variation of the loss moduli is observed, corresponding to the onset of the glass transition of the hard PCHC blocks. This temperature of transition is consistent with the one determined by DSC, indicating limited mixing of the two types of polycarbonate blocks and falling in the same range for the three block copolymers. Both loss and storage moduli of the triblock copolymers increase significantly with an increase of the hard block content, and all three block copolymers behave as soft elastomeric materials over the temperature range considered ( 75 to $150{ }^{\circ} \mathrm{C}$ ), with rubbery plateau moduli in the range of 200 to $100 \mathrm{kPa}$. These three triblock polycarbonate samples thus exhibit a solid-like rubber behavior with PCHC hard domains acting as transient cross-linkers and as fillers of the continuous low $T_{\mathrm{g}}$ POC soft matrix.

From Figure 4A, between 75 and $150{ }^{\circ} \mathrm{C}$, the storage modulus $G^{\prime}$ first smoothly decreased until $120{ }^{\circ} \mathrm{C}$ and then softened further beyond the glass transition temperature of PCHC domains for all three block copolymers. As anticipated, at all temperatures, the storage modulus for $\mathrm{P}(\mathrm{C}-\mathrm{O}-\mathrm{C})_{3}$ is the highest, followed by $\mathrm{P}(\mathrm{C}-\mathrm{O}-\mathrm{C})_{2}$ and $\mathrm{P}(\mathrm{C}-\mathrm{O}-\mathrm{C})_{1}$. The fact that the $G^{\prime}$ values do not precipitously dip above the $T_{\mathrm{g}}$ of PCHC, hard domains indicate that microphase separation still prevails and that these materials are still far from their orderdisorder transition (ODT) temperature which was found by DSC equaled to $184{ }^{\circ} \mathrm{C}$ (Figure S15). Changes in the loss modulus $G^{\prime \prime}$ with temperature look also of specific interest. It is important to notice that similar to the storage modulus, a change in the slope with the onset of the glass transition temperature is observed in the loss modulus of the three block copolymers. Unlike the distinct difference in the value of the 

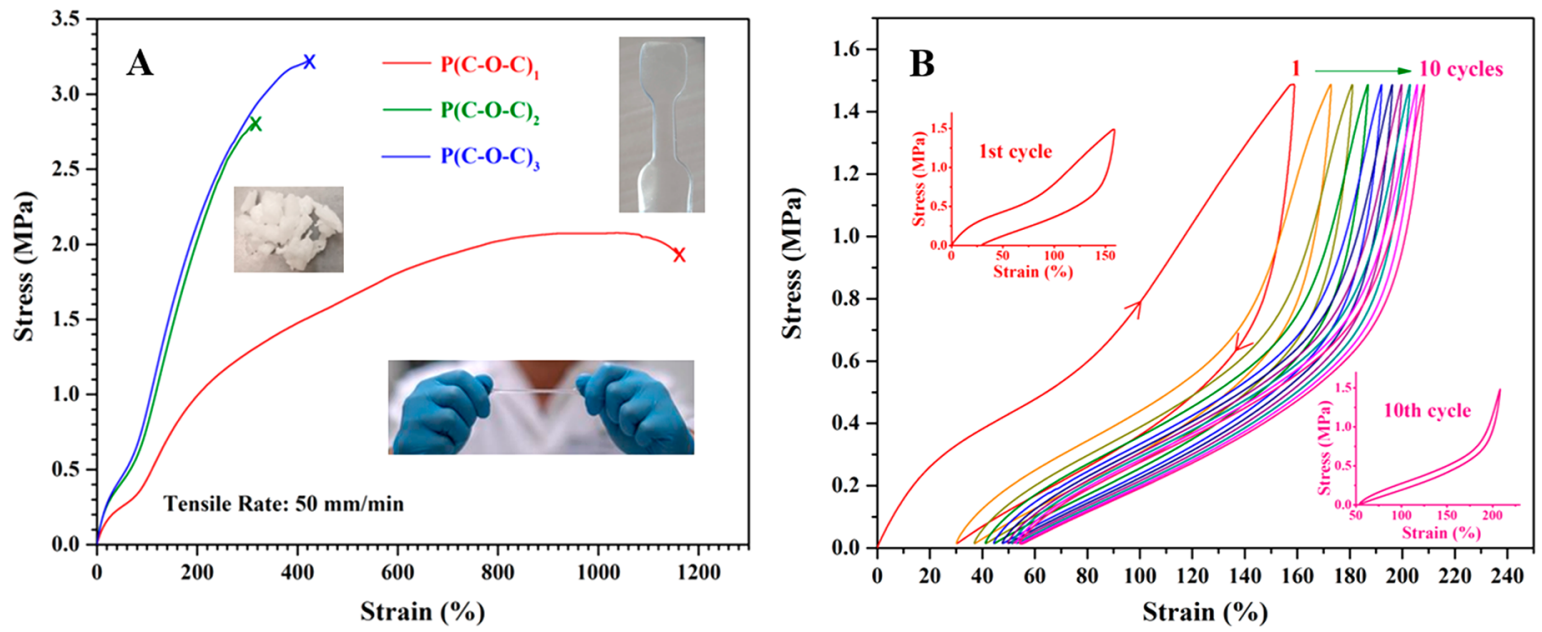

Figure 5. (A) Stress-strain curves for the tensile bars made from PCHC- $b$-POC- $b$-PCHC triblock copolymers with the insets being photos of asprepared triblock copolymers and tensile bars with original shape and under stretching; (B) cyclic tensile curve for $\mathrm{P}(\mathrm{C}-\mathrm{O}-\mathrm{C})_{3}$ with ultimate stress of $1.5 \mathrm{MPa}$ and no delay between cycles.

storage modulus $\left(\mathrm{G}^{\prime}\right)$ for $\mathrm{P}(\mathrm{C}-\mathrm{O}-\mathrm{C})_{2}$ and $\mathrm{P}(\mathrm{C}-\mathrm{O}-\mathrm{C})_{1}$ at all temperatures, the loss modulus $\left(G^{\prime \prime}\right)$ for $\mathrm{P}(\mathrm{C}-\mathrm{O}-\mathrm{C})_{2}$ and $\mathrm{P}(\mathrm{C}-\mathrm{O}-\mathrm{C})_{1}$ overlaps below the glass transition temperature of the hard block. Deviation in the value of $G^{\prime \prime}$ occurs in the two block copolymers with the onset of the glass transition temperature. This variation with temperature is suggestive of the changes in the dissipation of energy in the two block copolymers with the applied strain, above the glass transition temperature. Data on the phase angle $\left(G^{\prime \prime} / G^{\prime}\right)$ are provided in Figure S16.

The dynamic frequency sweep experiments (Figure 4B,C) corroborate the above conclusion. As can be seen from the variation of $\log \left(G^{\prime}, G^{\prime \prime}\right)$ versus $\log \omega$ at 100 and $150{ }^{\circ} \mathrm{C}$, there is no indication that the terminal region where the material would behave as viscous fluid is close by. Even at $150{ }^{\circ} \mathrm{C}$, the power law relationship between $G^{\prime}$ and $G^{\prime \prime}$ on the one hand and $\omega$ on the other does not scale as $G^{\prime \prime} \approx \omega$ and $G^{\prime} \approx \omega^{2}$ which is typical of the terminal region. ${ }^{34}$ The decrease of the $G^{\prime}$ when comparing its values at 100 and $150{ }^{\circ} \mathrm{C}$ is due to the softening of PCHC hard domains above their $T_{\mathrm{g}}\left(\approx 120^{\circ} \mathrm{C}\right)$ but not caused by ODT.

Dynamic frequency sweep experiments provide further information on the changes in the loss modulus of the three block copolymers. Similar to the temperature sweep experiments (Figure 4A), the frequency sweep experiments (Figure $4 \mathrm{~B}, \mathrm{C}$ ) show that the loss modulus of the two block copolymers $\mathrm{P}(\mathrm{C}-\mathrm{O}-\mathrm{C})_{2}$ and $\mathrm{P}(\mathrm{C}-\mathrm{O}-\mathrm{C})_{1}$ overlap in a specific frequency range and tend to demerge at lower frequencies, i.e., at longer times. The frequency at which the loss moduli of the two block copolymers demerge is found to be strongly influenced by the temperature above $\left(30 \mathrm{rad} / \mathrm{s}, 150{ }^{\circ} \mathrm{C}\right)$ and below $(1 \mathrm{rad} / \mathrm{s}, 100$ $\left.{ }^{\circ} \mathrm{C}\right)$ the glass transition temperature of the hard block. These findings strongly suggest that the dissipation or loss of the energy that is likely to occur via the soft block is strongly influenced in the two block copolymers by the rigidity of the hard block. It takes longer time (low frequency) for energy to dissipate below the glass transition temperature of the hard block compared to that above the glass transition temperature. At low frequencies, the rate at which the loss modulus decreases is slower for $\mathrm{P}(\mathrm{C}-\mathrm{O}-\mathrm{C})_{2}$ compared to $\mathrm{P}(\mathrm{C}-\mathrm{O}-$ C) ${ }_{1}$. This further confirms the role of hard block in dissipation of the energy via the soft block.
Near parallel slopes of the storage modulus $G^{\prime}$ of the three samples (Figure 4A), approximated to the plateau modulus in the low temperature region, allowed us to estimate the molar mass between entanglements $\left(M_{\mathrm{e}}\right)$ of the soft block at a specific temperature. Using the Guth-Smallwood approximation that assumes that spherical hard domains act as fillers in a rubber, we could derive the molar mass between entanglements for the soft block of $\mathrm{P}(\mathrm{C}-\mathrm{O}-\mathrm{C})_{1}$ and $\mathrm{P}(\mathrm{C}-\mathrm{O}-\mathrm{C})_{2}$ (the two copolymers exhibiting a spherical morphology of hard blocks, Figure 3) from the plateau modulus, $G_{n}(\Phi)$, via the following equation:

$$
\mathrm{G}_{\mathrm{n}}(\Phi)=\mathrm{G}_{\mathrm{n}}^{0}\left(1+2.5 \Phi+14.1 \Phi^{2}\right)
$$

where $G_{n}^{0}$ is the plateau modulus of the POC component and $\Phi$ the volume fraction of PCHC hard blocks. The molar mass between entanglements $\left(M_{\mathrm{e}}\right)$ in such triblock copolymers is given by $M_{\mathrm{e}}=\rho \mathrm{RT} / \mathrm{G}_{\mathrm{n}}^{0}$, where $\rho$, the density, is taken equal to $1.2 \mathrm{~g} / \mathrm{cm}^{3}$ and $R$, the universal gas constant, is equal to $8.314 \mathrm{~J} /(\mathrm{mol} \cdot \mathrm{K})$. At the specific temperature of $75^{\circ} \mathrm{C}(348 \mathrm{~K})$, $\mathrm{G}_{\mathrm{n}}(\Phi)$ are respectively equal to $1.04 \mathrm{MPa}$ for $\mathrm{P}(\mathrm{C}-\mathrm{O}-\mathrm{C})_{1}$ and 1.4 MPa for $\mathrm{P}(\mathrm{C}-\mathrm{O}-\mathrm{C})_{2}$ the following values of $\mathrm{M}_{e}$ are obtained for the two block copolymers exhibiting sphere-type morphologies: $M_{e \mathrm{P}(\mathrm{COC}) 1}=62000 \mathrm{~g} / \mathrm{mol}$ and $M_{\mathrm{eP}(\mathrm{COC}) 2}=55$ $000 \mathrm{~g} / \mathrm{mol}$. To recall, the relatively low $M_{e}$ values for polybutadiene $=1700 \mathrm{~g} / \mathrm{mol}$ results in a higher modulus of the SBS triblock copolymer compared to those of the SIS copolymers or poly(isooctyl acrylate)-based copolymers; the $M_{e}$ values of polyisoprene is $6100 \mathrm{~g} / \mathrm{mol}$ and that of poly(isooctyl acrylate) is $60000 \mathrm{~g} / \mathrm{mol}$. The very high $M_{e}$ of POC suggests ease in deformation of the soft component, which has been addressed while measuring the tensile strength of these samples. (For details on the calculations please refer to the Table S1).

To evaluate the mechanical properties of the triblock copolymers, the latter were extruded using a mini twin screw extruder and the extrudate was molded directly into a dog bone resulting in transparent and colorless samples (insets in Figure 5A). The mechanical characterization of the dog-bone shaped tensile bars was carried out through tensile tests. The stress-strain curves for these samples are shown in Figure 5A; they are characterized by moderate moduli and high elongations at the break which is typical of an elastomeric 
behavior. Accordingly all three samples recover their original shape upon release of the stress and do not exhibit any plastic deformation even at high deformation. The tensile strength of the triblock copolymers is $2.04,2.76$, and $3.24 \mathrm{MPa}$, respectively, which increases with the hard block content. In this work, we decided to focus on samples exhibiting purely elastomeric behavior and not to prepare samples with higher content in PCHC blocks which might have displayed higher tensile strength through strain hardening behavior typical of ductile plastics. The largest elongation at break (1052\%) was observed for $\mathrm{P}(\mathrm{C}-\mathrm{O}-\mathrm{C})_{1}$, and $331 \%$ and $454 \%$ elongations were obtained for $\mathrm{P}(\mathrm{C}-\mathrm{O}-\mathrm{C})_{2}$ and $\mathrm{P}(\mathrm{C}-\mathrm{O}-\mathrm{C})_{3}$ although the latter included a higher content in $\mathrm{PCHC}$ hard block.

Cyclic tensile tests were performed with $\mathrm{P}(\mathrm{C}-\mathrm{O}-\mathrm{C})_{3}$ to check the elastic recovery property of the elastomer. The tensile bars were stretched to a maximum of $1.5 \mathrm{MPa}$ of stress and then released to zero stress. A total of 10 cycles were conducted with no delay time between cycles. As can be seen in Figure 5B, the elastic modulus decreased gradually with each cycle, which may result from a decrease in size of the hard domains. $^{36}$ The recovery rate is accessible through the following equation: recovery rate $=\left(\varepsilon_{\max }-\varepsilon_{\text {residual }}\right) / \varepsilon_{\max }$ where $\varepsilon_{\max }$ represents the maximum strain at the applied stress and $\varepsilon_{\text {residual }}$ denotes the residual strain after releasing the stress. $\varepsilon_{\text {max }}$ at $1.5 \mathrm{MPa}$ for the first cycle was $159 \%$ and the $\varepsilon_{\text {residual }}$ was $30 \%$, revealing a recovery rate of $81 \%$; the residual strain increased after each cycle, but the increment in residual strain decreased from $30 \%$ to $0.14 \%$ after 10 cycles along with a remarkable decrease in hysteresis loss. An orientation in the polymer chain due to stretching is believed to be the reason for this trend. As determined from the cyclic tensile curves (Figures $\mathrm{S} 17$ and $\mathrm{S} 18)$, the recovery rate for $\mathrm{P}(\mathrm{C}-\mathrm{O}-\mathrm{C})_{1}$ and $\mathrm{P}(\mathrm{C}-\mathrm{O}-\mathrm{C})_{2}$ in one cycle of stretching and releasing is $83 \%$ and $82 \%$, respectively.

Biodegradable thermoplastic elastomers entirely made of polycarbonate blocks have thus been synthesized to serve as materials with comparable characteristics to those currently used in tissue engineering and regenerative medicine. ${ }^{37-39}$ In particular, thermoplastic elastomers with low to moderate elastic modulus are indeed shown to be more suitable for soft tissue engineering applications with specific compliance requirements. Moderate moduli can reduce the mismatch between the implants and soft tissues, the elasticity allowing a shape recovery when large strains are applied in dynamic mechanical environments. The Young moduli of the $\mathrm{CO}_{2}^{-}$ based polycarbonate thermoplastic elastomers synthesized in this work are in the range of 1.4-2.5 MPa. Some soft living tissues such as vascular elastin and knee cartilage were found to be in $0.3-10 \mathrm{MPa}$ range. ${ }^{40,41}$ Our materials that are totally made of polycarbonates and entirely degradable may find applications in tissue engineering, thanks to their mechanical compatibility with the above living tissues.

\section{CONCLUSIONS}

We demonstrated in this investigation the versatility of the TEB-mediated copolymerization of epoxides with $\mathrm{CO}_{2}$ that was applied to the synthesis of well-defined all-polycarbonate triblock copolymers made of a central soft POC block flanked by two external hard PCHC blocks. The "living" character of these polycarbonate synthesis and the ease with which the content and the size of the copolymer blocks can be varied indicate that the TEB-mediated system of copolymerization of $\mathrm{CO}_{2}$ with epoxides can be used for a broad range of applications, from coating and adhesives (low content in $\mathrm{PCHC}$ ) to ductile plastics (high content of PCHC) or soft rubbers. In this work we focused on this type of material that require essentially thermodynamic incompatibility between the soft blocks and the hard glass blocks. The mechanical properties of such elastomers then depend also on the molar mass between entanglements and the glass transition temperature. We could clearly demonstrate the existence of phase separation between the soft matrix (POC) and the glassy hard domains acting as fillers. Both spherical and cylindrical morphologies could be identified depending upon the content of PCHC blocks. Because of the rather large molar mass between entanglements and because certainly some compatibilization between the two types of polycarbonate blocks occurred, the storage modulus values, tensile strength, and the Young modulus values of these polycarbonate block copolymers were typical of soft rubbers, behaving as pure rubbers with no yield point and strain-hardening behavior. Prior to the synthesis of these triblock all-polycarbonate copolymers, the anionic copolymerization of various epoxides with $\mathrm{CO}_{2}$ in the presence of TEB was investigated; the steric hindrance due to the substituent and the presence of an ether oxygen in the latter were found to decrease the reactivity of the corresponding epoxide. Upon increasing the bulkiness of the initiator cation and varying the amount of TEB used, all epoxides tried could be copolymerized with $\mathrm{CO}_{2}$ with a high linear versus cyclic selectivity so that alternating polycarbonates could be generated in all cases.

\section{ASSOCIATED CONTENT}

\section{(s) Supporting Information}

The Supporting Information is available free of charge at https://pubs.acs.org/doi/10.1021/acs.macromol.0c01068.

Experimental section, ${ }^{1} \mathrm{H}$ NMR spectra, DSC curves, phase angle data, and $\mathrm{M}_{\mathrm{e}}$ (Figure S1-S18 and Table S1) (PDF)

\section{AUTHOR INFORMATION}

\section{Corresponding Authors}

Yves Gnanou - Physical Sciences and Engineering Division and KAUST Catalysis Center, King Abdullah University of Science and Technology (KAUST), Thuwal 23955, Saudi Arabia; 이이.org/0000-0001-6253-7856; Email: yves.gnanou@ kaust.edu.sa

Xiaoshuang Feng - Physical Sciences and Engineering Division and KAUST Catalysis Center, King Abdullah University of Science and Technology (KAUST), Thuwal 23955, Saudi Arabia; 이이.org/0000-0001-7473-1728; Email: fxs101@ gmail.com

\section{Authors}

Mingchen Jia - Physical Sciences and Engineering Division and KAUST Catalysis Center, King Abdullah University of Science and Technology (KAUST), Thuwal 23955, Saudi Arabia

Dongyue Zhang - Physical Sciences and Engineering Division and KAUST Catalysis Center, King Abdullah University of Science and Technology (KAUST), Thuwal 23955, Saudi Arabia

Gijs W. de Kort - Aachen-Maastricht Institute of Biobased Materials (AMIBM), Maastricht University, Maastricht 6200MD, The Netherlands 
Carolus H. R. M. Wilsens - Aachen-Maastricht Institute of Biobased Materials (AMIBM), Maastricht University, Maastricht 6200MD, The Netherlands; 이이이.org/00000003-3063-9510

Sanjay Rastogi - Aachen-Maastricht Institute of Biobased Materials (AMIBM), Maastricht University, Maastricht

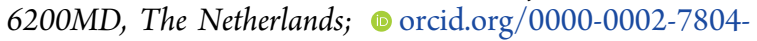
7349

Nikos Hadjichristidis - Physical Sciences and Engineering Division and KAUST Catalysis Center, King Abdullah University of Science and Technology (KAUST), Thuwal

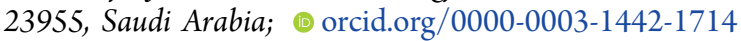

Complete contact information is available at: https://pubs.acs.org/10.1021/acs.macromol.0c01068

\section{Notes}

The authors declare no competing financial interest.

\section{ACKNOWLEDGMENTS}

This research work is supported by KAUST under baseline funding (BAS/1/1374-01-01).

\section{REFERENCES}

(1) Scharfenberg, M.; Hilf, J.; Frey, H. Functional Polycarbonates from Carbon Dioxide and Tailored Epoxide Monomers: Degradable Materials and Their Application Potential. Adv. Funct. Mater. 2018, 28, 1704302.

(2) Xu, Y.; Lin, L.; Xiao, M.; Wang, S.; Smith, A. T.; Sun, L.; Meng, Y. Synthesis and properties of $\mathrm{CO}_{2}$-based plastics: Environmentallyfriendly, energy-saving and biomedical polymeric materials. Prog. Polym. Sci. 2018, 80, 163-182.

(3) Wang, Y.; Darensbourg, D. J. Carbon dioxide-based functional polycarbonates: Metal catalyzed copolymerization of $\mathrm{CO}_{2}$ and epoxides. Coord. Chem. Rev. 2018, 372, 85-100.

(4) Inoue, S.; Koinuma, H.; Tsuruta, T. Copolymerization of carbon dioxide and epoxide. J. Polym. Sci., Part B: Polym. Lett. 1969, 7, 287292.

(5) Mandal, M. Group 4 complexes as catalysts for the transformation of $\mathrm{CO}_{2}$ into polycarbonates and cyclic carbonates. $J$. Organomet. Chem. 2020, 907, 121067.

(6) Andrea, K. A.; Plommer, H.; Kerton, F. M. Ring-opening polymerizations and copolymerizations of epoxides using aluminumand boron-centered catalysts. Eur. Polym. J. 2019, 120, 109202.

(7) Della Monica, F.; Buonerba, A.; Capacchione, C. Homogeneous Iron Catalysts in the Reaction of Epoxides with Carbon Dioxide. $A d v$. Synth. Catal. 2019, 361, 265-282.

(8) Lu, X.-B.; Ren, W.-M.; Wu, G.-P. $\mathrm{CO}_{2}$ copolymers from epoxides: catalyst activity, product selectivity, and stereochemistry control. Acc. Chem. Res. 2012, 45, 1721-1735.

(9) Kember, M. R.; Buchard, A.; Williams, C. K. Catalysts for $\mathrm{CO}_{2} /$ epoxide copolymerisation. Chem. Commun. 2011, 47, 141-163.

(10) Coates, G. W.; Moore, D. R. Discrete metal-based catalysts for the copolymerization of $\mathrm{CO}_{2}$ and epoxides: Discovery, reactivity, optimization, and mechanism. Angew. Chem., Int. Ed. 2004, 43, 66186639.

(11) Kim, I.; Yi, M. J.; Byun, S. H.; Park, D. W.; Kim, B. U.; Ha, C. S. Biodegradable Polycarbonate Synthesis by Copolymerization of Carbon Dioxide with Epoxides Using a Heterogeneous Zinc Complex. Macromol. Symp. 2005, 224, 181-192.

(12) Zhang, X.-H.; Wei, R.-J.; Zhang, Y. Y.; Du, B.-Y.; Fan, Z.-Q. Carbon Dioxide/Epoxide Copolymerization via a Nanosized ZincCobalt(III) Double Metal Cyanide Complex: Substituent Effects of Epoxides on Polycarbonate Selectivity, Regioselectivity and Glass Transition Temperatures. Macromolecules 2015, 48, 536-544.

(13) Zhang, D.; Boopathi, S. K.; Hadjichristidis, N.; Gnanou, Y.; Feng, X. Metal-Free Alternating Copolymerization of $\mathrm{CO}_{2}$ with
Epoxides: Fulfilling "Green" Synthesis and Activity. J. Am. Chem. Soc. 2016, 138, 11117-11120.

(14) Zhang, D.-D.; Feng, X.; Gnanou, Y.; Huang, K.-W. Theoretical Mechanistic Investigation into Metal-Free Alternating Copolymerization of $\mathrm{CO}_{2}$ and Epoxides: The Key Role of Triethylborane. Macromolecules 2018, 51, 5600-5607.

(15) Patil, N. G.; Boopathi, S. K.; Alagi, P.; Hadjichristidis, N.; Gnanou, Y.; Feng, X. Carboxylate Salts as Ideal Initiators for the Metal-Free Copolymerization of $\mathrm{CO}_{2}$ with Epoxides: Synthesis of Well-Defined Polycarbonates Diols and Polyols. Macromolecules 2019, 52, 2431-2438.

(16) Boopathi, S. K.; Hadjichristidis, N.; Gnanou, Y.; Feng, X. Direct access to poly (glycidyl azide) and its copolymers through anionic (co)polymerization of glycidyl azide. Nat. Commun. 2019, 10, 293.

(17) Chen, Z.; Yang, J.-L.; Lu, X.-Y.; Hu, L.-F.; Cao, X.-H.; Wu, G.P.; Zhang, X.-H. Triethyl borane-regulated selective production of polycarbonates and cyclic carbonates for the coupling reaction of $\mathrm{CO}_{2}$ with epoxides. Polym. Chem. 2019, 10, 3621-3628.

(18) Lukaszczyk, J.; Jaszcz, K.; Kuran, W.; Listos, T. Synthesis of functional polycarbonates by copolymerization of carbon dioxide with allyl glycidyl ether. Macromol. Rapid Commun. 2000, 21, 754-757.

(19) Deng, K.; Wang, S.; Ren, S.; Han, D.; Xiao, M.; Meng, Y. A Novel Single-Ion-Conducting Polymer Electrolyte Derived from $\mathrm{CO}_{2}$ Based Multifunctional Polycarbonate. ACS Appl. Mater. Interfaces 2016, 8, 33642-33648.

(20) Tominaga, Y.; Shimomura, T.; Nakamura, M. Alternating copolymers of carbon dioxide with glycidyl ethers for novel ionconductive polymer electrolytes. Polymer 2010, 51, 4295-4298.

(21) Darensbourg, D. J.; Wang, Y. Terpolymerization of propylene oxide and vinyl oxides with $\mathrm{CO}_{2}$ : copolymer cross-linking and surface modification via thiol-ene click chemistry. Polym. Chem. 2015, 6, $1768-1776$.

(22) Wang, Y.; Fan, J.; Darensbourg, D. J. Construction of Versatile and Functional Nanostructures Derived from $\mathrm{CO}_{2}$-based Polycarbonates. Angew. Chem., Int. Ed. 2015, 54, 10206-10210.

(23) Konieczynska, M. D.; Lin, X.; Zhang, H.; Grinstaff, M. W. Synthesis of Aliphatic Poly(ether 1,2-glycerol carbonate)s via Copolymerization of $\mathrm{CO}_{2}$ with Glycidyl Ethers Using a Cobalt Salen Catalyst and Study of a Thermally Stable Solid Polymer Electrolyte. ACS Macro Lett. 2015, 4, 533-537.

(24) Guo, J.-T.; Wang, X.-Y.; Xu, Y.-S.; Sun, J.-W. Copolymerizations of carbon dioxide and epoxides in the presence of rare earth coordinate catalyst. J. Appl. Polym. Sci. 2003, 87, 2356-2359.

(25) Jia, M. C.; Hadjichristidis, N.; Gnanou, Y.; Feng, X. S. Monomodal Ultrahigh-Molar-Mass Polycarbonate Homopolymers and Diblock Copolymers by Anionic Copolymerization of Epoxides with $\mathrm{CO}_{2}$. ACS Macro Lett. 2019, 8, 1594-1598.

(26) Kim, J. G.; Cowman, C. D.; LaPointe, A. M.; Wiesner, U.; Coates, G. W. Tailored Living Block Copolymerization: Multiblock Poly(cyclohexene carbonate)s with Sequence Control. Macromolecules 2011, 44, 1110-1113.

(27) Wang, Y.; Fan, J.; Darensbourg, D. J. Construction of Versatile and Functional Nanostructures Derived from $\mathrm{CO}_{2}$-based Polycarbonates. Angew. Chem., Int. Ed. 2015, 54, 10206-10210.

(28) Darensbourg, D. J.; Ulusoy, M.; Karroonnirum, O.; Poland, R. R.; Reibenspies, J. H.; Çetinkaya, B. Highly Selective and Reactive (salan) $\mathrm{CrCl}$ Catalyst for the Copolymerization and Block Copolymerization of Epoxides with Carbon Dioxide. Macromolecules 2009, 42, 6992-6998.

(29) Nakano, K.; Hashimoto, S.; Nakamura, M.; Kamada, T.; Nozaki, K. Stereocomplex of Poly (propylene carbonate): Synthesis of Stereogradient Poly (propylene carbonate) by Regio-and Enantioselective Copolymerization of Propylene Oxide with Carbon Dioxide. Angew. Chem., Int. Ed. 2011, 50, 4868-4871.

(30) Nakano, K.; Kamada, T.; Nozaki, K. Selective Formation of Polycarbonate over Cyclic Carbonate: Copolymerization of Epoxides with Carbon Dioxide Catalyzed by a Cobalt(III) Complex with a Piperidinium End-Capping Arm. Angew. Chem., Int. Ed. 2006, 45, 7274-7277. 
(31) Jiang, Y.-J.; Ren, W.-M.; Liu, Y.; Lu, X.-B. Synthesis of Polycarbonate Block Terpolymers Using Robust Cobalt Catalyst Systems. Chin. J. Polym. Sci. 2019, 37, 1200-1204.

(32) Yang, G.-W.; Wu, G.-P. High-Efficiency Construction of $\mathrm{CO}_{2}$ Based Healable Thermoplastic Elastomers via a Tandem Synthetic Strategy. ACS Sustainable Chem. Eng. 2019, 7, 1372-1380.

(33) McLean, R. S.; Sauer, B. B. Tapping-mode AFM studies using phase detection for resolution of nanophases in segmented polyurethanes and other block copolymers. Macromolecules 1997, 30, 83148317.

(34) Kim, J. K.; Lee, H. H.; Gu, Q.-J.; Chang, T.; Jeong, Y. H. Determination of order- order and order- disorder transition temperatures of SIS block copolymers by differential scanning calorimetry and rheology. Macromolecules 1998, 31, 4045-4048.

(35) Gruth, E. Theory of filler reinforcement. J. Appl. Phys. 1945, 16, 20-25.

(36) Bolton, J. M.; Hillmyer, M. A.; Hoye, T. R. Sustainable Thermoplastic Elastomers from Terpene-Derived Monomers. ACS Macro Lett. 2014, 3, 717-720.

(37) Serrano, M. C.; Chung, E. J.; Ameer, G. A. Advances and Applications of Biodegradable Elastomers in Regenerative Medicine. Adv. Funct. Mater. 2010, 20, 192-208.

(38) Bettinger, C. J. Biodegradable Elastomers for Tissue Engineering and Cell-Biomaterial Interactions. Macromol. Biosci. 2011, 11, 467-482.

(39) Levental, I.; Georges, P. C.; Janmey, P. A. Soft biological materials and their impact on cell function. Soft Matter 2007, 3, 299306.

(40) Gosline, J.; Lillie, M.; Carrington, E.; Guerette, P.; Ortlepp, C.; Savage, K. Elastic proteins: biological roles and mechanical properties. Philos. Trans. R. Soc., B 2002, 357, 121-132.

(41) Liu, Q. Y.; Zhang, L. Q.; Shi, R. Degradable bioelastomers: synthesis and biodegradation. RSC Green Chem. Ser. 2011, 0, 243290. 